\title{
SF-1771, A NEW ANTIBIOTIC RELATED TO BLEOMYCIN
}

\author{
Kazunori Ohba, Takashi Shomura, Takashi Tsuruoka, Shoji Omoto, ${ }^{*}$ \\ Michio Kojima, Takashi Hisamatsu, Shigeharu Inouye \\ and TARO NIIDA \\ Central Research Laboratories, Meiji Seika Kaisha, Ltd., \\ Morooka-cho, Kohoku-ku, Yokohama 222, Japan \\ (Received for publication August 14, 1980)
}

\begin{abstract}
A new antibiotic, substance SF-1771, has been isolated from the fermentation broth of Streptomyces toyocaensis SF-1771. The antibiotic is highly active against Gram-positive and -negative bacteria and effective against sarcoma 180 cells of ascites type in mice. It belonged to the phleomycin-bleomycin group antibiotics, but has been differentiated from the known antibiotics by the physicochemical properties, chromatographic behaviours and amino acid analysis.
\end{abstract}

In the course of our screening for new antibiotics, a novel basic antibiotic was isolated from the culture filtrate of Streptomyces toyocaensis SF-1771. The strain was isolated from a soil sample collected at Takehara city, Hiroshima prefecture, Japan. This paper deals with the production, isolation, purification and physico-chemical and biological properties of substance SF-1771.

\section{Characterization of the Producing Microorganism}

For the taxonomic characterization of the strain SF-1771, the methods of the International Streptomyces Project (ISP) by Shirling and GotTlieB ${ }^{1)}$ were used, with additional media recommended by WAKSMAN ${ }^{22}$. The strain SF-1771 showed the following morphological, cultural and physiological characteristics: Aerial mycelium indicated monopodial branching with spiral spore chains on most of the media tested. The spores were in chains of more than ten, ellipsoidal in shape, $0.8 \sim 1.1 \times 1.2 \sim$ $1.4 \mu$ in size and had spiny surfaces. On most media, the aerial mass color was gray to brownish gray and the reverse color was pale yellow to grayish yellow. The strain SF-1771 showed good growth with abundant aerial mycelia in most of media except for sucrose-nitrate agar. No soluble pigment was formed. The strain utilized D-glucose, D-fructose, D-mannose and inositol but did not utilize Dxylose, L-arabinose, rhamnose, sucrose and raffinose. LL-Diaminopimeric acid was detected in the whole cell hydrolyzates. Based on the characteristics described above, the strain SF-1771 evidently belonged to genus Streptomyces, among which, Streptomyces toyocaensis ${ }^{3)}$ was most closely related. Therefore, Streptomyces toyocaensis ISP 5030 was directly compared with the strain SF-1771 by simultaneous cultivation, and the results are shown in Table 1. Except for utilization of L-arabinose and cultural characteristics on oatmeal agar and nutrient agar, morphological and physiological properties were in good agreement between the two strains. The differences were not sufficient to designate the strain SF-1771 as a new species, and it was named Streptomyces toyocaensis SF-1771.

* To whom inquiries should be addressed. 


\section{Production of SF-1771 Substance}

Streptomyces toyocaensis $\mathrm{SF}-1771$ was grown at $28^{\circ} \mathrm{C}$ for 7 days on yeast extract-starch agar slants. The inoculum was prepared by suspending the spores from each slant in $10 \mathrm{ml}$ of sterile water, and planting in medium containing $1.0 \%$ soluble starch and $3.0 \%$ soybean meal $(\mathrm{pH} 7.0$ ) in shaking flasks. The seed culture which was prepared by incubation at $28^{\circ} \mathrm{C}$ for 40 hours in a reciprocal shaker was transferred into a 50-liter jar fermentor, containing 35 liters of the medium containing $4.0 \%$ sucrose, $1.0 \%$ soybean oil, $3.0 \%$ soybean meal, $2.0 \%$ wheat embryo, $0.6 \%$ sodium chloride and $0.003 \% \mathrm{CuSO}_{4} \cdot 5 \mathrm{H}_{2} \mathrm{O}(\mathrm{pH} 7.0)$. Fermentation was carried out at $28^{\circ} \mathrm{C}$ for 114 hours under aeration. The antibiotic titer was assayed against Bacillus subtilis ATCC 6633 by the usual paper-disc method.

\section{Isolation and Purification of SF-1771 Substance}

The culture broth fermented for 114 hours ( $\mathrm{pH} 6.8)$ was filtered with diatomaceous earth $(5 \% \mathrm{w} / \mathrm{v})$. The filtrate (20 liters) was adsorbed on a column of Amberlite XAD-2 (2 liters). The column was washed with 20 liters of water and the antibiotic adsorbed on the resin was eluted with 14 liters of $50 \%$ aqueous acetone ( $\mathrm{pH} 3.0)$. The active fractions (9 liters) were adjusted to $\mathrm{pH} 6.0$ with $1 \mathrm{~N}$ sodium hydroxide and concentrated to remove acetone. This was passed through a column of CM-Sephadex C-25 (250 ml), the column was washed with 2.5 liters of water, then with $0.1 \mathrm{M}$ sodium chloride, and the antibiotic was eluted with $0.2 \mathrm{M}$ aqueous sodium chloride. Effluents were collected in $20 \mathrm{ml}$ portions, No. $125 \sim 150$ were combined and adsorbed on a column of Diaion HP-20 (0.3 liter). The column was washed with $200 \mathrm{ml}$ of water and eluted with $500 \mathrm{ml}$ of $50 \%$ aqueous methanol. The active fraction was concentrated to a small volume and lyophilized to give a yellowish green powder of crude SF-1771 substance (320 mg). The crude powder was further purified by a column chromatography of CM-Sephadex C-25, developed with $0.15 \mathrm{M}$ aqueous sodium chloride. Active eluate was passed through a column of HP-20 for desalting. The $50 \%$ methanol eluate was concentrated to dryness for further purification. This was dissolved in 70\% aqueous methanol, passed through a 400-ml column of Sephadex LH-20 and developed with $90 \%$ aqueous methanol. Evaporation of solvent from the active effluent gave a blue powder of substance SF-1771 as a copper-chelated hydrochloride (42 mg).

A pale yellow powder of copper-free SF-1771 substance was obtained by treating the methanolic solution of copper-complex with hydrogen sulfide followed by chromatography over Sephadex LH-20. So far, no minor component has been detected during column chromatography.

\section{Physico-chemical Properties}

SF-1771, obtained as a blue amorphous hydrochloride, was readily soluble in water, soluble in methanol, slightly soluble in ethanol and insoluble in other organic solvents. It was stable in acidic solution but unstable in alkaline solution. It did not give a definite melting point, but gradually changed to brown around $185^{\circ} \mathrm{C}$ and decomposed at $208^{\circ} \mathrm{C}$. 
Fig. 1. Ultraviolet absorption spectrum of SF-1771 in water.

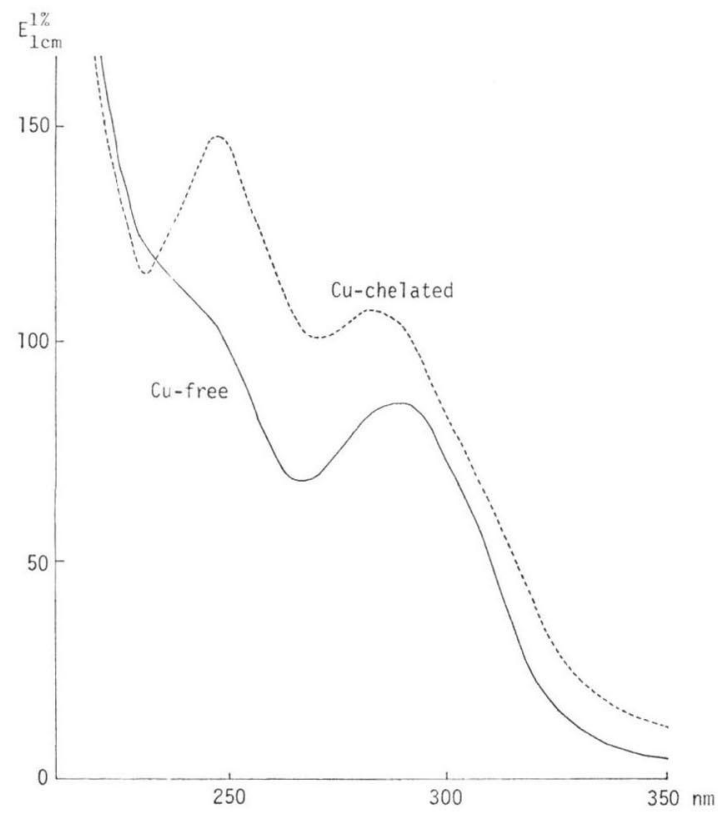

Table 2. Rf values of SF-1771 substance and related compounds in silica gel TLC.

\begin{tabular}{l|c|c|c}
\hline & \multicolumn{3}{|c}{ Solvent system and Rf } \\
\cline { 2 - 4 } & $\mathrm{A}$ & $\mathrm{B}$ & $\mathrm{C}$ \\
\hline SF-1771 substance & 0.68 & 0.57 & 0.83 \\
Bleomycin $\mathrm{A}_{2}$ & 0.37 & 0.36 & - \\
Bleomycin $\mathrm{B}_{2}$ & 0.64 & 0.65 & - \\
Bleomycin $\mathrm{A}_{5}$ & 0.54 & 0.52 & - \\
Bleomycin $\mathrm{B}_{4}$ & 0.54 & 0.51 & - \\
Victomycin & 0.64 & 0.51 & - \\
Platomycin A & 0.64 & 0.53 & - \\
Platomycin B & 0.52 & 0.45 & - \\
Zorbonomycin B & 0.65 & - & 0.88 \\
Tallysomycin A & 0.18 & 0.04 & 0.80 \\
Tallysomycin B & 0.21 & 0.06 & 0.79 \\
\hline Solvent A 10 &
\end{tabular}

Solvent A : $10 \%$ Ammonium acetate-methanol $(1: 1)$.

B : Methanol - $10 \%$ ammonium acetate $10 \%$ ammonium water $(10: 9: 1)$.

C: $n$-Propanol - pyridine - acetic acid water $(15: 10: 3: 12)$.

Fig. 2. CM-Sephadex chromatography of SF-1771, bleomycin (Bleo), victomycin (Victo), platomycins (Plato.).

Column: CM-Sephadex C-25 (i.d. $8 \mathrm{~mm} \times 15 \mathrm{~cm}$ )

Elution: $0 \sim 1.0 \mathrm{M}$ ammonium formate

Flow rate: $15 \mathrm{ml} /$ hour

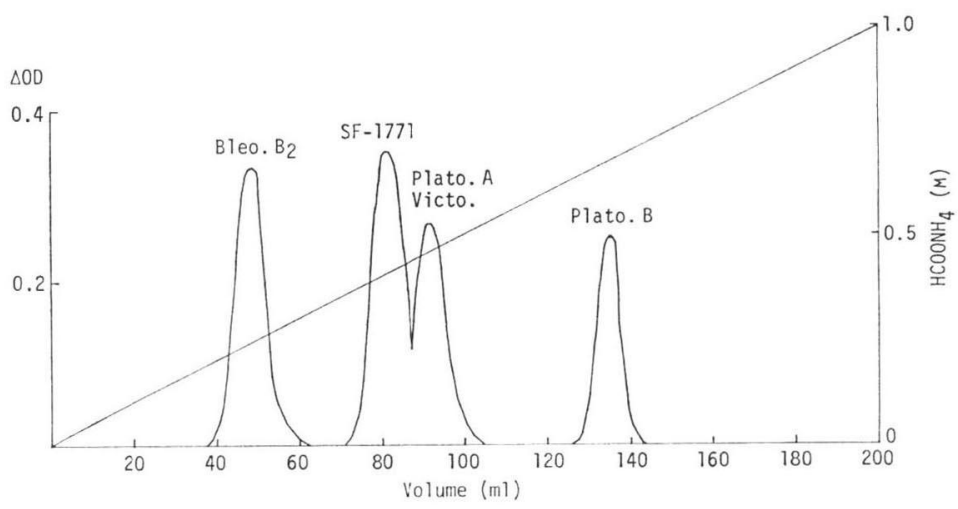

The elemental analysis was: $\mathrm{C}, 38.70 ; \mathrm{H}, 5.42 ; \mathrm{N}, 13.03 ; \mathrm{O}, 29.62 ; \mathrm{S}, 3.62 ; \mathrm{Cl}, 6.07$ and $\mathrm{Cu}, 3.53 \%$. From the elemental analysis, approximate molecular formula $\mathrm{C}_{58} \mathrm{H}_{94} \mathrm{~N}_{17} \mathrm{O}_{33} \mathrm{~S}_{2} \mathrm{Cu} \cdot 3 \mathrm{HCl}$ was suggested for SF-1771.

As shown in Fig. 1, copper-chelated SF-1771 hydrochloride showed UV maxima at $248 \mathrm{~nm}\left(\mathrm{E}_{1 \mathrm{~cm}}^{1 \%}\right.$ 146) and $282 \sim 284 \mathrm{~nm}\left(\mathrm{E}_{1 \mathrm{~cm}}^{1 \%}\right.$ 106). The intensity ratio of the two absorption maxima at $248 \mathrm{~nm}$ and $282 \sim 284 \mathrm{~nm}$ was 1.38. SF-1771 hydrochloride (copper-free) showed $[\alpha]_{\mathrm{D}}^{20}-18.4^{\circ}\left(c 1, \mathrm{H}_{2} \mathrm{O}\right)$. Color reactions to GreIG-LeAback, LemiEUX, Ehrlich were positive but negative to ninhydrin and SAKAGUCHI 
Fig. 3. IR spectrum of SF-1771 hydrochloride (KBr pellet).

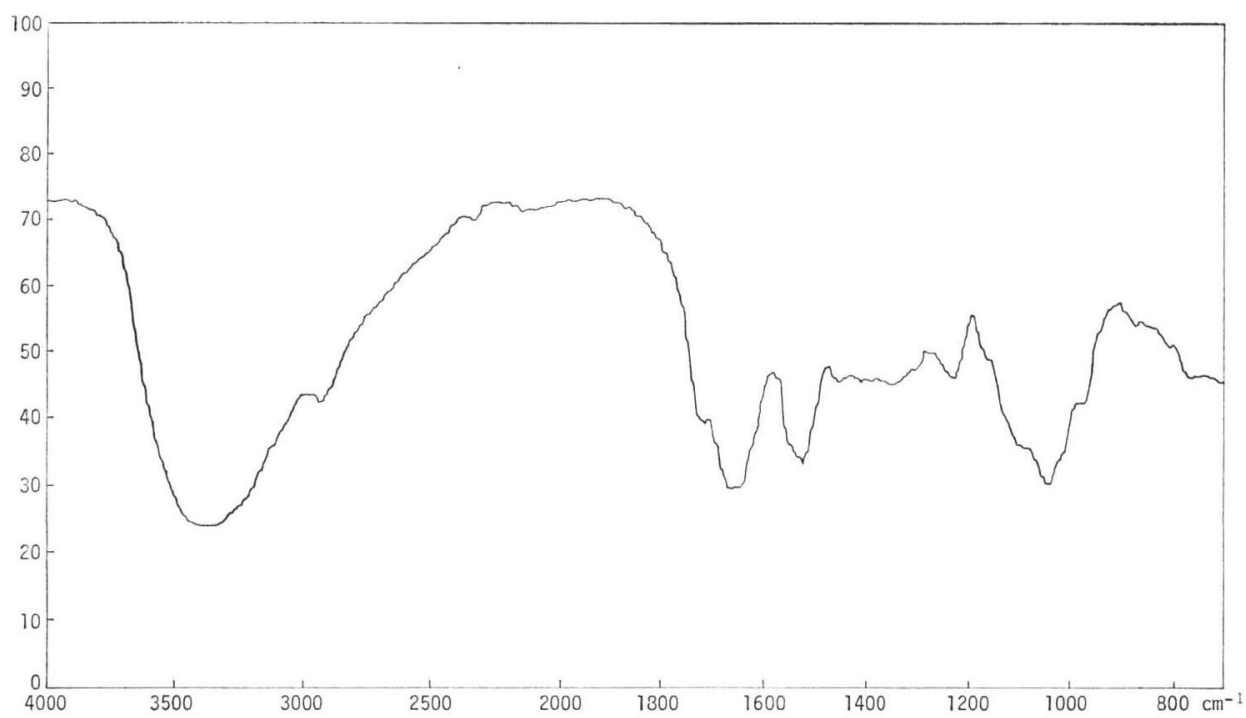

Fig. 4. ${ }^{1} \mathrm{H}-\mathrm{NMR}$ spectrum of SF-1771 (Cu-free) $\quad\left(100 \mathrm{MHz}\right.$ in $\left.\mathrm{D}_{2} \mathrm{O}\right)$.

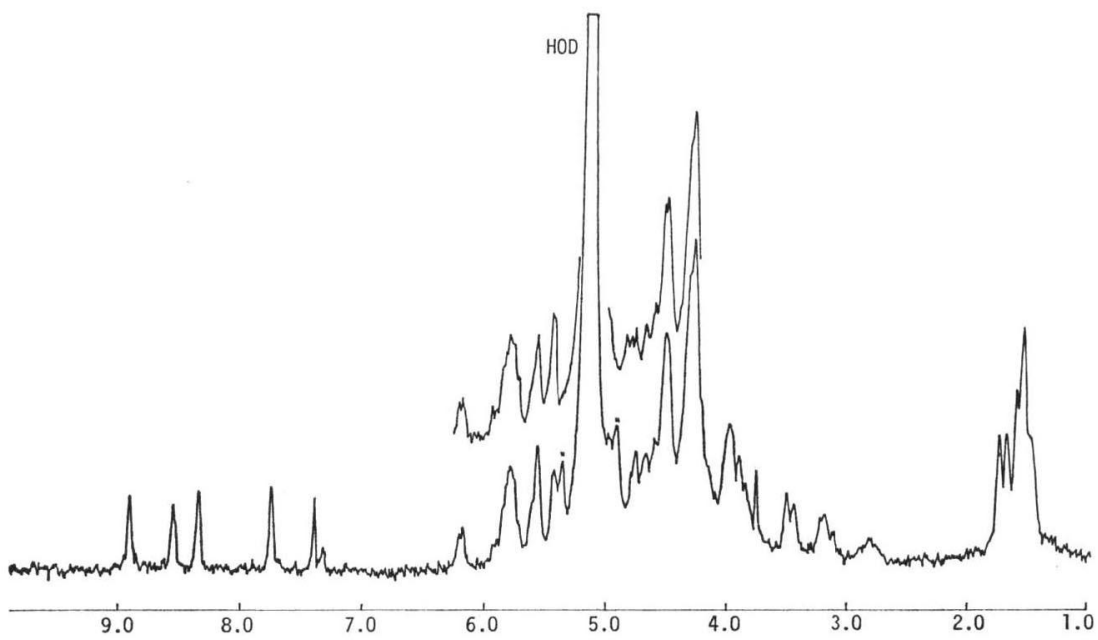

ppm from external TMS

reactions. Rf values on silica gel TLC and relative elution volume on a CM-Sephadex column of SF-1771 and some other related compounds are shown in Table 2 and Fig. 2. The IR spectrum of copper-free form in $\mathrm{KBr}$ pellet is presented in Fig. 3. Strong absorptions are observed at $3400 \sim 3200 \mathrm{~cm}^{-1}(\mathrm{OH} /$ $\mathrm{NH}), 1720 \mathrm{~cm}^{-1}\left(\mathrm{OCONH}_{2}\right), 1650$ and $1550 \mathrm{~cm}^{-1}$ (CONH) and $1120 \sim 1020 \mathrm{~cm}^{-1}$ (C-O-).

The ${ }^{1} \mathrm{H}-\mathrm{NMR}$ spectrum of copper-free hydrochloride is shown in Fig. 4.

Biological Properties of SF-1771

The minimum inhibitory concentration (MIC) of SF-1771 was determined by the agar dilution method, and the results are given in Table 3. It showed strong antibacterial activity against Gram- 
Table 3. Antimicrobial spectrum of copper-free SF-1771.

\begin{tabular}{|c|c|}
\hline Test organisms & $\begin{array}{c}\text { MIC } \\
(\mathrm{mcg} / \mathrm{ml})\end{array}$ \\
\hline Staphylococcus aureus JC-1 & 0.78 \\
\hline Staphylococcus aureus S-424 & 50 \\
\hline Staphylococcus epidermidis ATCC 14990 & 12.5 \\
\hline Staphylococcus epidermidis 109 & 12.5 \\
\hline Streptococcus faecalis ATCC 8043 & $>100$ \\
\hline Bacillus anthracis No. 119 & 6.25 \\
\hline Escherichia coli JC-2 & 0.39 \\
\hline Escherichia coli No. 29 & 1.56 \\
\hline Escherichia coli RGN 823 & 0.39 \\
\hline Escherichic coli JR 66/W 677 & 0.39 \\
\hline Citrobacter freundii GN 346 (CSase; H) & 0.78 \\
\hline Salmonella typhi 0-901-W & 0.39 \\
\hline Salmonella typhimurium LT-2 & 0.39 \\
\hline Salmonella enteritidis No. 11 & 0.39 \\
\hline Sarcina lutea & 12.5 \\
\hline Shigella sonnei EW 33 Type 1 & 0.78 \\
\hline Klebsiella pneumoniae PCI 602 & 0.78 \\
\hline Klebsiella pneumoniae $22 \# 3038$ & 100 \\
\hline Proteus vulgaris OX 19 & 1.56 \\
\hline Proteus rettgeri $\mathrm{J}-0026$ & 50 \\
\hline Proteus morganii Kono & 3.13 \\
\hline Serratia marcescens MB-3848 & 50 \\
\hline Pseudomonas aeruginosa MB-3829 & $>100$ \\
\hline Pseudomonas cepacia M-0527 & 25 \\
\hline
\end{tabular}

positive and -negative bacteria. Table 4 showed the antitumor activity against sarcoma 180 of mouse ascites type. SF-1771 (copper-free) was most effective by intraperitoneal administration of $4 \mathrm{mg} / \mathrm{kg} /$ day. It was inactive against leukemia L-12:10 in mice.

The $\mathrm{LD}_{50}$ of copper-chelated and copper-free forms were about $10 \mathrm{mg} / \mathrm{kg}$ and $20 \mathrm{mg} / \mathrm{kg}$ respectively, by intravenous injection to mice. It showed negative mutagenecity test (rec assay) when examined by the streak and paper disc method using a mutant of Bacillus subtilis as a test organism. The relative rate of inactivation against rat liver enzyme of SF-1771 (copper-free) and bleomycin $\mathrm{A}_{2}$ was compared.

This antibiotic was evidently more stable than bleomycin $\mathrm{A}_{2}$ against $100 \mathrm{~S}$ fraction of rat liver homogenate, as shown in Table 5.

Table 4. Antitumor activity of SF-1771 (Cu-free) against sarcoma 180 ascites type.

\begin{tabular}{c|c|r}
\hline Dose $(\mathrm{mg} / \mathrm{kg} / \text { day })^{*}$ & $\begin{array}{c}\text { Mean survival } \\
\text { days }\end{array}$ & ILS (\%) \\
\hline 8 & 31.4 & 78.4 \\
4 & 36.8 & 109.1 \\
2 & 37.2 & 111.4 \\
1 & 29.0 & 64.8 \\
Control & 17.6 & - \\
\hline * The daily intraperitoneal injection of SF-1771 \\
(Cu-free) for 3 days was started 24 hours after \\
the intraperitoneal transplantation of $1.14 \times$ \\
10 tumor cells.
\end{tabular}

Table 5. Inactivation of $\mathrm{SF}-1771$ substance $(\mathrm{Cu}-$ free) by $100 \mathrm{~S}$ fractions of rat liver homogenates.*

\begin{tabular}{c|r|r|c|c|c}
\hline \multirow{2}{*}{ Substance } & \multicolumn{4}{|c}{ Survival of activity (\%) } \\
\cline { 2 - 6 } & 1 hr. & 3 hrs. & 6 hrs. & 10 hrs. & 24 hrs. \\
\hline SF-1771 (Cu-free) & 100 & 100 & 80 & 52 & 28 \\
$\begin{array}{c}\text { Bleomycin } A_{2} \\
\text { (Cu-free) }\end{array}$ & 76 & 64 & 40 & 34 & $<6$ \\
\hline
\end{tabular}

* The inactivating reaction was carried out at $34^{\circ} \mathrm{C}$, pH $7.5(1 / 30 \mathrm{M}$ phosphate buffer) and the remaining activity of the antibiotic was assayed by the paper disc method.

I

Demethyl-II

III

IV

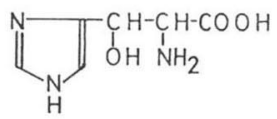

V

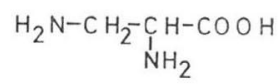

$\mathbf{V I}^{\prime}$<smiles></smiles> 


\section{Discussion}

From the physico-chemical and biological properties described above, SF-1771 substance seems to belong to the bleomycin-phleomycin antibiotic. From the ratio of two UV maxima at 248 and $282 \sim 284 \mathrm{~nm}(1.38), \mathrm{SF}-1771$ substance is more similar to bleomycins ${ }^{4)}$, cleomycin ${ }^{5)}$, phleomycin $\left(\mathrm{C}, \mathrm{D}_{2}\right.$ and $\mathrm{F})^{8)}$, zorbonomycin ${ }^{7)}$, victomycin ${ }^{8)}$, platomycin $(\mathrm{A} \text { and } \mathrm{B})^{9)}$ and tallysomycins ${ }^{10)}$ rather than phleo-

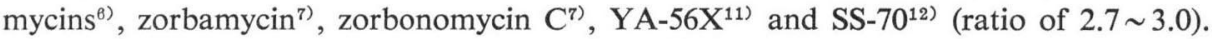

The negative SAKAGUCHI reaction of SF-1771 further differentiated the B group of bleomycins, victomycin and platomycins, all of which gave positive SAKAGUCHI reaction ${ }^{13,14)}$. SF-1771 seemed to be different from any other bleomycin group antibiotics including zorbonomycin B and tallysomycins as judged from various chromatographic systems.

The novelty of SF-1771 was strongly supported by degradation studies of it. Gulose and 3-Ocarbamoyl-mannose, common sugar moieties of all bleomycins, were found to be sugar components of SF-1771 by GC-MS analysis of its methanolyzate, however, SF-1771 was found to possess unique amino acid components. It is still not clear whether an amino sugar is present, as found in tallysomycins, or not, however, CMR spectrum of SF-1771 suggested the presence of an extra sugar at $96.0 \mathrm{ppm}$. TLC (Avicel) coupled with high voltage electrophoresis ( $\mathrm{pH} 1.8$ ) of acid hydrolyzate of SF-1771 revealed the presence of six ninhydrin positive spots, in which four spots were identified as threonine (I)*, 4-amino-3-hydroxy-2-methyl- $n$-valeric acid (III)*, $\beta$-hydroxy-histidine $(I V)^{*}$ and $\beta$-aminoalanine (V)*. The spot corresponding to $\beta$-amino- $\beta$-(4-amino-6-carboxy-5-methylpyrimidin-2-yl)-propionic acid (II)* was not detected, however, the compound with lowest mobility on TLC seemed to be demethyl-II ${ }^{15 a, b)}$ judging from its ninhydrin-coloration and its $\mathrm{Rf}$ value.

Finally, this amino acid was identified as $\beta$-amino- $\beta$-(4-amino-6-carboxy-pyrimidin-2-yl)-propionic acid (demethyl-II) by the direct comparison with an authentic sample ${ }^{18)}$. In the ${ }^{1} \mathrm{H}-\mathrm{NMR}$ spectrum of SF-1771, no aromatic methyl signal was observed around $3 \mathrm{ppm}$ region and instead, an extra olefin proton assignable to H-5 in demethyl-II was observed in the lowest field region of the spectrum. All bleomycin group antibiotics so far reported possessed II in common and demethyl-II was only found, in the biosynthetic intermediates of bleomycin isolated from the culture broth of Streptomyces verticillus. ${ }^{15 a, b)}$ Therefore, SF-1771 is the first bleomycin-phleomycin group antibiotic possessing demethyl-II instead of II. ${ }^{1} \mathrm{H}-\mathrm{NMR}$ spectrum of SF-1771 also suggested the presence of a bithiazole component, however, 2'-(2-aminoethyl)-2,4'-bithiazole-4-carboxylic acid (VI)* could not be detected in acid hydrolyzate. Since 2'-polyfunctionally substituted bithiazole carboxylic acid (VI') was reported to decompose during acid hydrolysis ${ }^{18)}, \mathrm{SF}-1771$ was considered to contain $\mathbf{V I}^{\prime}$ type of compound. It is also interesting that no terminal amine component found in bleomycins was found in SF-1771.

We have also isolated another bleomycin group antibiotic possessing demethyl-II, SF-1961, whose detail is given in the following paper ${ }^{19)}$.

\section{Acknowledgement}

We wish to thank Dr. Hamao Umezawa, Dr. Tomohisa Takita and their associates of Institute of Microbial Chemistry for their kind guidance and advice for the chemical analysis. Thanks are also due to Dr. TAKASHI NARA of Kyowa Hakko Kogyo Ltd., for the sample of victomycin, platomycin A and B, to Dr. A. D. Argoudelis of the Upjohn Company, for zorbonomycin B, to Dr. T. OKUDA of Microbial Chemistry Research Laboratory, Tanabe Seiyaku Co. Ltd., for YA-56 X and Y, and to Dr. M. KonIsH of Bristol-Banyu Research Institute, Ltd. for tallysomycin $\mathrm{A}$ and $\mathrm{B}$.

\section{References}

1) Shirling, E. B. \& D. Gottlieb: Methods of characterization of Streptomyces species. Intern. J. Syst. Bact. 16: 313 340, 1966

2) Waksman, S. A.: Classification, identification and description genera and species. The actinomycetes

* These designations adopted here for the component in SF-1771 correspond to those in bleomycin group antibiotics $^{17 \mathrm{a}, \mathrm{b})}$. 
Vol. 11, p. 328. The Williams \& Wilkins Co., Baltimore, U.S.A., 1961

3) Shirling, E. B. \& D. GotTlieb: Cooperative description of type cultures of Streptomyces. II. Species description of first study. Intern. J. Syst. Bact. 18: 174, 1968

4) Umezawa, H.; Y. Suhara, T. Takita \& K. Maeda: Purification of bleomycins. J. Antibiotics, Ser. A 19: $210 \sim 215,1966$

5) Muraoka, Y.; A. Fumin, H. Naganawa, T. Takita \& H. Umezawa: Chemical structure of cleomycin, a new antibiotic related to bleomycin-phleomycin group antibiotics. 55th Annual Meeting of Agricultural Chemical Society of Japan, Abstract, 1P-25, Fukuoka, April, 1 4, 1980

6) Ikekawa, T.; F. Iwami, H. Hiranaka \& H. Umezawa: Separation of phleomycin components and their properties. J. Antibiotics, Ser. A 17: 194 199, 1964

7) Argoudelis, A. D.; M. E. Bergy \& T. R. Pyke: Zorbamycin and related antibiotics. I. Production, isolation and characterization. J. Antibiotics 24: 543 557, 1971

8) Takasawa, S.; I. Kawamoto, R. OKachi, M. Kohakura, R. Yahashi \& T. Nara: A new antibiotic victomycin (XK-49-1-B-2). II. Isolation, purification and physicochemical and biological properties. J. Antibiotics 28: 366 371, 1975

9) Takasawa, S.; I. Kawamoto, S. Sato, R. Yahashi, R. Okachi, M. Yamamoto, T. Sato \& T. Nara: Platomycins A and B. II. Physicochemical properties. J. Antibiotics 28: 662 667, 1975

10) Kawaguchi, H.; H. Tsukiura, K. Tomita, M. Konishi, K. Sato, S. Kobaru, K. Numata, K. Fujisawa, T. Miyake, M. Hatori \& H. Koshiyama: Tallysomycin, a new antitumor antibiotic related to bleomycin. I. Production, isolation and properties. J. Antibiotics 30: 779 788, 1977

11) Ito, Y.; Y. Ohashi, S. Kawabe, M. Sakurazawa, T. Ogawa, Y. Egawa \& T. Okuda: The antibiotic YA-56 complex: Isolation, purification and physicochemical properties of main components. J. Antibiotics 26: 77 83, 1973

12) Ohba, K.; M. Kojma, T. Tsuruoka, Y. Ogawa, H. Watanabe, S. Inouye \& T. Niida: Studies on new antibiotics; SS-70-A and B substance. Sci. Reports of Meiji Seika Kaisha 16: 29 36, 1976

13) Umezawa, H.; K. Maeda, T. Takeuchi \& Y. Okami: New antibiotics, bleomycin A and B. J. Antibiotics, Ser. A 19: 200 209, 1966

14) Fuji, A.; T. Takita, K. Maeda \& H. Umezawa: New components of bleomycin. J. Antibiotics 26: $396 \sim 397,1973$

15) a) Nakatani, T.; K. Ishikawa, Y. Muraoka, A. Fuji, H. Naganawa, T. Takita \& H. Umezawa: Biosynthesis of bleomycin. Isolation and structure studies of peptide fragments. 53th Annual Meeting of the Agricultural Chemical Society of Japan, Abstract 2P-16, Nagoya, April 2 4, 1978

b) Irtaka, Y.; H. Nakamura, T. Nakatani, Y. Muraoka, A. Fuji, T. Takita \& H. Umezawa: Chemistry of bleomycin. XX. The X-ray structure determination of P-3A Cu(II)-complex, a biosynthetic intermediate of bleomycin. J. Antibiotics 31: 1070 1072, 1978

16) We thank Dr. T. TAKITA of Institute of Microbial Chemistry for generous sample of demethyl-II.

17) a) Takita, T.; Y. Muraoka, K. Maeda \& H. Umezawa: Chemical studies on bleomycins. I. The acid hydrolysis products of bleomycin $\mathrm{A}_{2}$. J. Antibiotics 21: 79 80, 1968

b) Muraoka, Y.; T. Takita, K. Maeda \& H. Umezawa: Chemistry of bleomycin. IV. The structure of amine component II of bleomycin $\mathrm{A}_{2}$. J. Antibiotics 23: 252 253, 1970

18) Konishi, M.; K. Sato, K. Numata, T. Tsuno, K. Asama, H. Tsukiura, T. Naito \& H. Kawaguchi: Tallysomycin, a new antitumor antibiotic complex related to bleomycin. II. Structure determination of tallysomycins A and B. J. Antibiotics 30: 789 804, 1977

19) Shomura, T.; S. Omoto, K. Ohba, H. Ogino, M. Kojma \& S. Inouye: SF-1961, a new antibiotic related to bleomycin. J. Antibiotics 33: 1243 1248, 1980 